Jurnal Satyagraha

Vol.04, No.01, Pebruari 2021 - Agustus 2021

ISSN : 2620-6358

http://ejournal.universitasmahendradatta.ac.id/index.php/satyagraha

\title{
PENGARUH KOMUNIKASI, BUDAYA ORGANISASI, DAN LINGKUNGAN KERJA TERHADAP KEPUASAN KERJA KARYAWAN
}

\author{
Ni Luh Gede Putu Purnawati ${ }^{1}$, Ida Ayu Nyoman Yuliastuti ${ }^{2}$, Pande Ketut ribek ${ }^{3}$ ) \\ 1,3 Program Studi Manajemen, Fakultas Ekonomi dan Bisnis \\ Jalan KambojaNo.11A Denpasar 80223 \\ ${ }^{2}$ Program Studi Akuntansi, Fakultas Ekonomi dan Bisnis \\ Jalan KambojaNo.11A Denpasar 80223 \\ Email:purnawati0505@gmail.com
}

\begin{abstract}
Abstrak
Suatu perusahaan akan dapat berjalan dengan baik jika terciptakanya suatu hubungan yang harmonis dari segi komunikasi yang baik dan dikukung oleh budaya dan lingkungan yang nyaman. Penelitian ini bertujuan agar dapat mengetahui pengaruh komunikasi, budaya organisasi, dan lingkungan kerja terhadap kepuasan kerja di Mizu Villa. Populasi dalam yang digunakan penelitian ini adalah seluruh karyawan yang bekerja pada Mizu Villa, KutaBali. Dengan demikian jumlah populasi, yaitu sebanyak 30 orang. Dimana teknik penentuan sampel yang digunakan merupakan metode sampel jenuh, yaitu metode penentuan sampel menggunakan seluruh populasi yang dijadikan sampel didalam penelitian, sehingga jumlah responden yang digunakan adalah sebanyak 30 orang. Teknik analisis data yang digunakan dalam penelitian ini yaitu analisis regresi linier berganda. Hasil dari penelitian ini menunjukkan bahwa komunikasi, budaya organisasi dan lingkungan kerja fisik berpengaruh positif dan signifikan terhadap kepuasan kerja, berarti semakin baiknya komunikasi yang terjadi, semakin kuat budaya organisasi yang terbentuk dan semakin baik pula kondisi lingkungan kerja di Mizu Villa, maka akan semakin tinggi kepuasan kerja yang dirasakan oleh para karyawan
\end{abstract}

Kata kunci: komunikasi, budaya organisasi, lingkungan kerja fisik, kepuasan kerja

\begin{abstract}
A company will be able to run well if it creates a harmonious relationship in terms of good communication and is supported by a culture and a comfortable environment. This study aims to determine the effect of communication, organizational culture, and work environment on job satisfaction at Mizu Villa. The population used in this study were all employees who work at Mizu Villa, Kuta-Bali. Thus the total population is 30 people. Where the sampling technique used is a saturated sample method, namely the method of determining the sample using the entire population sampled in the study, so that the number of respondents used is 30 people. The data analysis technique used in this study is multiple linear regression analysis. The results of this study indicate that communication, organizational culture and physical work environment have a positive and significant effect on job satisfaction, meaning that the better communication occurs, the stronger the organizational culture is formed and the better the working conditions at Mizu Villa, the higher job satisfaction felt by employees
\end{abstract}

Keywords: communication, organizational culture, physical work environment, job satisfaction

Ni Luh Gede Putu Purnawati

Pande Ketut ribek 
Jurnal Satyagraha

Vol.04, No.01, Pebruari 2021 - Agustus 2021

ISSN : 2620-6358

http://ejournal.universitasmahendradatta.ac.id/index.php/satyagraha

\section{PENDAHULUAN}

Perusahaan pada umumnya memiliki tujuan yang pasti, tujuan jangka pendek atau tujuan jangka panjang. Untuk realisasikan tujuan tersebut, perusahaan dapat memanfaatkan beberapa faktor produksi yang dimilikinya, antara lain sumber daya alam, sumber daya manusia, modal, dan keahlian Suatu perusahaan dalam menjalankan aktivitasnya akan selalu berhadapan dengan manusia yang merupakan sumber daya yang dinamis dan memiliki suatu kemampuan untuk menciptakan suatu inovasi baru. Sumber daya manusia merupakan suatu aset yang dianggap paling berharga yang dimiliki oleh suatu organisasi, karena manusia merupakan satu-satunya sumber daya yang dapat menggerakkan sumber daya lainnya. Menurut (Tjutju, 2008), sumber daya manusia merupakan aset organisasi yang sangat vital, karena itu peran dan fungsinya tidak bisa digantikan oleh sumber daya lainnya.

Faktor lain yang mempengaruhi kinerja menurut (Kriyantono, 2009) adalah kepuasan kerja pada pegawai yang berada dalam organisasi tersebut. Kepuasan kerja merupakan respon yang berbeda dari setiap pegawai, kepuasan menjadi respon atau tanggapan seseorang terhadap beragam lingkungan kerja yang dihadapinya. Kepuasan kerja dan komunikasi positif akan menciptakan kinerja pegawai dalam suatu organisasi dengan baik. Organisasi merupakan kualitas yang relatif abadi dari lingkungan internal organisasi yang dialami oleh anggota-anggotanya, memengaruhi tingkah laku mereka serta dapat diuraikan dalam istilah nilai-nilai suatu karakteristik tertentu dari lingkungan.

Kepuasan kerja berpengaruh terhadap kinerja pegawai yang muncul dari kombinasi berbagai faktor, diantaranya kepuasan dengan pekerjaan yang dikerjakan, gaji yang diterima, sikap atasan, dan perilaku rekan kerja. Hal ini diyakini banyak organisasi sebagai faktor utama kepuasan kerja, karena ada sebagian pegawai yang merasa bahwa kepuasan dari sebuah pekerjaan diperoleh ketika mereka telah menyelesaikan pekerjaan yang ditugaskannya.

Komunikasi merupakan poin yang paling penting dan sebagai penunjang dalam meningkatkan kepuasan kerja karyawan. Dengan adanya komunikasi yang baik setiap individu dapat menyampaikan pendapat antara satu dengan lainnya, baik 
Jurnal Satyagraha

Vol.04, No.01, Pebruari 2021 - Agustus 2021

ISSN : 2620-6358

http://ejournal.universitasmahendradatta.ac.id/index.php/satyagraha

melalui verbal atau non verbal. Semakin baik komunikasi yang dijalin satu dengan lainnya maka akan semakin cepat pula terjalinnya suatu hubungan kerja. Budaya organisasi juga dapat mempengaruhi kepuasan kerja karyawan dalam suatu organisasi. Budaya organisasi merupakan filosofi dasar organisasi yang memuat keyakinan, norma-norma, dan nilai-nilai bersama yang menjadi suatu karakter yang dapat mencerminkan cara melaksanakan sesuatu dalam organisasi (Wibowo, 2010). Budaya organisasi dibentuk oleh para individu, dalam organisasi, etika organisasi yang diterapkan, hak karyawan yang diberikan kepada tiap orang dan juga merupakan jenis struktur organisasi dari organisasi yang bersangkutan. Dengan demikian budaya organisasi menjadikan suatu pedoman yang mampu menopang mencapai tujuan organisasi.

Selain faktor tersebut, dapat mempengaruhi kepuasan kerja karyawan ialah lingkungan kerja fisik. Karena lingkungan kerja yang mendukung akan mendorong aktifitas didalam suatu perusahaan, serta akan menumbuhkan semangat dan gairah kerja karyawan. Hal ini dirasa bermanfaat bagi pertumbuhan hidup suatu perusahaan dan akan dapat meningkatkan produktivitas sehingga tercapainya tujuan suatu perusahaan. Apabila suatu lingkungan yang kurang baik seperti suara bising, suhu udara panas, kebersihan tidak terjaga, dan sebagainya dapat menurunkan kondisi fisik dan kondisi mental karyawan. Indikasi penurunan kondisi fisik dapat berupa kelelahan, kelesuan kerja, gangguan kesehatan atau sakit, akibat kerja bahkan kecelakaan kerja (Robbins, 2008).

Mizu Villa adalah salah satu villa yang terletak di Kuta dengan lokasi yang strategis tepatnya di Jalan Pantai Berawa, Tibubeng, Kuta Utara, Badung, Bali. Villa tersebut mulai beroprasi pada tahun 2010 dengan menyedikan fasilitas lengkap dan memadai seperti terdapatnya kolam renang pribadi dan juga dapur pribadi. Secara teoritis kepuasan kerja karyawan tercermin dari beberapa indikator, salah satu diantaranya adalah tingkat absensi karyawan. Adapun tingkat absensi karyawan pada Mizu Villa dapat dilihat pada Tabel 1, sebagai berikut: 
Jurnal Satyagraha

Vol.04, No.01, Pebruari 2021 - Agustus 2021

ISSN : 2620-6358

http://ejournal.universitasmahendradatta.ac.id/index.php/satyagraha

Tabel 1

Tingkat Absenai Karyawan Mizu Villa 2019

\begin{tabular}{|l|l|l|l|l|l|}
\hline \multicolumn{1}{|c|}{ Bulan } & \multicolumn{1}{|c|}{$\begin{array}{c}\text { Jlh. } \\
\text { Pegawai }\end{array}$} & $\begin{array}{c}\text { Hari Kerja } \\
\text { Efektif }\end{array}$ & $\begin{array}{c}\text { Total Hari Kerja } \\
\text { Efektif/Bulan }\end{array}$ & Total & $\begin{array}{c}\text { Persentase } \\
\text { Tingkat } \\
\text { absensi (\%) }\end{array}$ \\
\hline A & $\mathbf{B}$ & $\mathbf{C}$ & $\mathbf{D = B x C}$ & $\mathbf{F}$ & $\mathbf{H = F / D . 1 0 0}$ \\
Jan. & 10 & 25 & 250 & 3 & $\mathbf{1 , 2}$ \\
Feb. & 10 & 24 & 240 & 5 & $\mathbf{2 , 1}$ \\
Mar. & 10 & 25 & 250 & 7 & $\mathbf{2 , 0 8}$ \\
Apr. & 10 & 24 & 240 & 3 & $\mathbf{1 , 2 5}$ \\
Mei & 10 & 26 & 260 & 5 & $\mathbf{1 , 9 2}$ \\
Juni & 10 & 26 & 260 & 7 & $\mathbf{2 , 6 9}$ \\
Juli & 10 & 26 & 260 & 9 & $\mathbf{3 , 4 6}$ \\
Agt & 10 & 25 & 250 & 8 & $\mathbf{3 , 2}$ \\
Sept. & 10 & 24 & 240 & 10 & $\mathbf{4 , 1 6}$ \\
Okt. & 10 & 24 & 240 & 7 & $\mathbf{2 , 9 1}$ \\
Nov. & 10 & 25 & 250 & 11 & $\mathbf{4 , 4}$ \\
Des. & 10 & 25 & 250 & 10 & $\mathbf{4 , 8}$ \\
\hline Sun & & & & \\
\hline
\end{tabular}

Sumber: Mizu Villa (2019)

Berdasarkan Tabel 1 dapat dijelaskan

bahwa jumlah persentase tingkat absensi

pada Mizu Villa pada tahun 2019 masih

dianggap kurang baik karena memiliki

nilai persentase lebih dari 3 persen.

Tingkat kehadiran karyawan perbulan yang masih dianggap baik menurut (Riduwan dan Sunarto, 2007) adalah berkisar 2 sampai 3 persen, sedangkan tingkat absensi 3 persen keatas menunjukkan rendahnya disiplin kerja karyawan. Hal tersebut mengindikasikan bahwa tingkat disiplin kerja karyawan masih perlu ditingkatkan, karena dengan banyaknya karyawan yang tidak hadir dapat menyebabkan suatu kegiatan operasional perusahaan terlaksana dengan

baik dan pekerjaan tidak dapat terselesaikan tepat pada waktunya.

Indikasi rendahnya kepuasan kerja karyawan Mizu Villa di Kuta yang masih kurang optimal dalam bekerja juga dapat dilihat dari beberapa karyawan yang masih menggunakan jam kerja untuk istrahat, contohnya saat jam kerja masih ada karyawan yang terlihat mengobrol dan bermain dengan gawainya. Selain itu masih ada juga beberapa karyawan yang suka datang terlambat dan pulang kerja lebih awal, yang membuktikan bahwa kepuasan kerja karyawan pada Mizu Villa di Kuta masih perlu ditingkatkan. Dari data tersebut dipaparkan pada Tabel 2 sebagai berikut:

Ni Luh Gede Putu Purnawati 
Jurnal Satyagraha

Vol.04, No.01, Pebruari 2021 - Agustus 2021

ISSN : 2620-6358

http://ejournal.universitasmahendradatta.ac.id/index.php/satyagraha

Tabel 2

Data Kerja Terlambat dan Pulang Kerja Lebih Awal Pada Mizu Villa

Tahun 2019

\begin{tabular}{|lcc|}
\hline Bulan & \multicolumn{2}{c|}{ Banyak Kejadian } \\
\cline { 2 - 3 } Januari & Datang Terlambat & Pulang Lebih Awal \\
Februari & 2 & 1 \\
Maret & 3 & 2 \\
April & 1 & 4 \\
Mei & 4 & 2 \\
Juni & 2 & 3 \\
Juli & 3 & 2 \\
Agustus & 3 & 2 \\
September & 2 & 3 \\
Oktober & 1 & 1 \\
Novemer & 2 & 2 \\
Desember & 4 & 3 \\
\hline
\end{tabular}

Pada Tabel 2 dapat disimak bahwa karyawan yang datang kerja terlambat dan pulang kerja lebih awal dikatakan cukup banyak, apabila fenomena ini dibiarkan terus-menerus maka nantinya dapat menimbulkan meningkatnya kejadian yang sama dan akan memberi dampak negatif bagi karyawan. Kondisi tersebut perlu diperhatikan oleh pihak manajemen supaya tidak terjadi berkelanjutan.

Permasalahan budaya organisasi yang terjadi pada Mizu Villa di Kuta antara lain dalam hak kedisiplinan waktu yang masih kurang baik pelaksanannya. Contohnya masih ada karyawan yang terlambat datang untuk bekerja. Padahal setiap bulan pemilik dari Mizu Villa melakukan kunjungan rutin untuk mengecek karyawannya, meskipun sudah cukup sering melakukan pertemuan rutin dengan harapan karyawan terbuka terhadap segala hal atau permasalahan yang dialami pada saat bekerja sehingga kepuasan kerja pada karyawan dapat terwujud, tapi masih ada beberapa keluhan dari karyawan terkait dengan komunikasi seperti tidak adanya bertegur sapa sehingga kurangnya komunikasi antar karyawan satu dengan lainnya.

Selain komunikasi yang merupakan suatu cara dalam meningkatkan kepuasan, budaya organisasi juga penting bagi perusahaan itu sendiri. Supaya karyawan merasa terbiasa dengan suatu aturan yang menjadi pokok keyakinan perusahaan dengan tujuan atau manfaat untuk mengatasi segala masalah yang timbul di perusahaan tersebut. Lingkungan kerja pada Mizu Villa Kuta menjadi pusat perhatian untuk dapat meningkatkan kepuasan kerja karyawan. Dengan demikian, yang perlu menjadi perhatian di lingkungan kerja Mizu Villa di Kuta adalah ruangan, penerangan, kendala dalam ruangan, keadaan sirkulasi udara (temperatur). Terdapat beberapa keluhan dari karyawan terhadap lingkungan kerja fisik seperti penerangan yang kurang dan ruangan loker yang sempit sehingga menyulitkan karyawan pada saat menaruh barang pribadinya, sempitnya ruangan dapur karyawan, sehingga membuat 


\section{Jurnal Satyagraha \\ Vol.04, No.01, Pebruari 2021 - Agustus 2021 \\ ISSN : 2620-6358}

http://ejournal.universitasmahendradatta.ac.id/index.php/satyagraha

karyawan bingung mencari tempat untuk beristirahat makan ataupun untuk bersantai dengan nyaman.

Adanya suatu permasalahan yang ditemui berkaitan dengan komunikasi, budaya organisasi, dan lingkungan kerja dalam suatu usaha meningkatkan kepuasan kerja karyawan maka bertujuan dari penelitian ini untuk mengetahui pengaruh komunikasi, budaya organisasi, dan lingkungan kerja terhadap kepuasan kerja karyawan pada Mizu Villa di Kuta

\section{LANDASAN TEORI}

1.Resource Based View (RBV)

Teori Resource Based View (RBV) dipelopori pertama kali oleh Wernerfelt (1984). Teori RBV ini memandang bahwa sumber daya dan kemampuan perusahaan penting bagi perusahaan, karena merupakan pokok atau dasar dari

\section{METODE}

Metode Penelitian ini dapat digolongkan sebagai penelitian kuantitatif. Menurut (Umar, 2008) penelitian kuantitatif dilaksanakan dengan mendefinisikan dan mengukur data kuantitatif, dan statistik objektif melalui suatu perhitungan ilmiah yang berasal dari sampel atas sejumlah pertanyaan tentang survei untuk menentukan frekuensi dan persentase respon mereka.

Penelitian ini dilakukan di Villa Mizu yang berlokasi di Jl. Pantai Berawa Tibubeneng, Kuta Utara, Badung, Bali, Indonesia. Alasan memilih lokasi ini, karena terdapat indikasi rendahnya kepuasan kerja karyawan yang terlihat dari tingginya tingkat absensi karyawan perbulan dan juga banyak suatu kejadian karyawan yang kedatangannya terlambat
Kabupaten Badung.

Berdasarkan telaah dan kajian penelitian terdahulu, dapat simpulkan hipotesis sebagai berikut: H1: komunikasi berpengaruh positif dan signifikan terhadap kepuasan kerja karyawan, $\mathrm{H} 2$ : budaya organisasi berpengaruh positif dan signifikan terhadap kepuasan kerja karyawan, H3: lingkungan kerja fisik berpengaruh positif dan signifikan terhadap kepuasan kerja karyawan.

kemampuan daya saing serta kinerja perusahaan. Asumsi dari teori RBV yaitu mengenai bagaimana suatu perusahaan dapat bersaing dengan perusahaan lain, dengan mengelola sumber daya yang dimiliki perusahaan yang bersangkutan sesuai dengan kemampuan perusahaan dalam mencapai keunggulan kompetitif perusahaan.

dan pulang lebih awal dari waktu yang ditentukan oleh perusahaan.

Populasi dalam penelitian ini ialah seluruh karyawan yang bekerja pada Villa Mizu di Kuta. Dengan jumlah populasi dalam penelitian ini sebanyak 30 orang. Teknik sampling yang digunakan adalah sampling jenuh. Menurut (Sugiyono, 2016), sampling jenuh ialah metode penentuan sampel apabila semua anggota populasi ingin digunakan sebagai sampel, hal tersebut sering dilaksanakan apabila jumlah populasi relatif kecil.

Penelitian ini menerapkan metode analisis data, seperti analisis regresi linier berganda. Analisis regresi linier berganda mempunyai makna untuk mengetahui besarnya pengaruh komunikasi, budaya organisasi dan lingkungan kerja fisik 
Jurnal Satyagraha

Vol.04, No.01, Pebruari 2021 - Agustus 2021

ISSN : 2620-6358

http://ejournal.universitasmahendradatta.ac.id/index.php/satyagraha

terhadap kepuasan kerja karyawan pada

\section{HASIL DAN PEMBAHASAN}

Hasil data tersebut diperoleh dari hasil kuesioner yang telah disebarkan kepada seluruh responden penelitian sejumlah 30 orang karyawan di Mizu Villa Bali.
Mizu Villa di Kuta.

Karakteristik responden diantaranya jenis kelamin, umur, tingkat pendidikan, dan lama kerja. kesimpulan mengenai karakteristik dari 30 orang responden dapat dilihat pada Tabel 3 berikut ini:

Tabel 3. Karakteristik Responden

\begin{tabular}{|l|l|l|l|l|}
\hline No. & Karakteristik & Klasifikasi & Jlh. Responden & \% \\
\hline \multirow{2}{*}{1} & \multirow{2}{*}{ Jenis Kelamin } & Laki-Laki & 10 & 33 \\
\cline { 3 - 5 } & & Perempuan & 20 & 67 \\
\hline \multirow{3}{*}{2} & \multirow{3}{*}{ Umur } & $21-30$ & 12 & 40 \\
\cline { 3 - 5 } & & $31-40$ & 13 & 43 \\
\hline \multirow{3}{*}{3} & $41-50$ & 5 & 17 \\
\hline \multirow{3}{*}{4} & Pendidikan & SMA & 5 & 17 \\
\cline { 3 - 5 } & \multirow{2}{*}{ Lama Kerja } & Diploma & 15 & 50 \\
\cline { 3 - 5 } & Sarjana & 10 & 33 \\
\hline & & $1-2$ tahun & 10 & 33 \\
\cline { 3 - 5 } & $2-4$ tahun & 15 & 17 \\
\cline { 3 - 5 } & $>4$ tahun & 5 & \\
\hline
\end{tabular}

Sumber: Mizu Villa (2019)

Tabel 3 menjelaskan bahwa banyak pegawai laki-laki dibandingkan perempuan yang bekerja di Mizu Villa. Diprediksi dari segi usia, mencerminkan bahwa pegawai yang bekerja di Mizu Villa mayoritas yang berusia 31-40 tahun. Data tersebut juga menjelakan bahwa karyawan di Hotel Mizu Villa paling dominan ialah lulusan sarjana yang dianggap sudah mampu memenuhi standar sebagai karyawan hotel yang memiliki kompetensi untuk mencapai tujuan organisasi diperusahaan.

\section{Tabel 4. Uji Validitas dan Reliabilitas}

Penggolongan pada responden berdasarkan masa kerja mencerminkan bahwa sebagian besar karyawan di Mizu Villa memiliki masa kerja 2 sampai 4 tahun yang mencerminkan bahwa karyawan Mizu Villa mempunyai sebuah komitmen organisasi yang tinggi, karena mampu memiliki masa kerja selama lebih dari 4 tahun.

Hasil rekapitulasi uji validitas dan reliabilitas dalam penelitian ini disajikan dalam Tabel 4 sebagai berikut:

\begin{tabular}{|l|l|l|}
\hline Variabel & Cronbach's Alpha & Keterangan \\
\hline Komunikasi $\left(\mathrm{X}_{1}\right)$ & 0,823 & Valid/Rel. \\
\hline Budaya Organisasi $\left(\mathrm{X}_{2}\right)$ & 0,782 & Valid/Rel. \\
\hline Lingkungan Kerja $\left(\mathrm{X}_{3}\right)$ & 0,833 & Valid/Rel. \\
\hline Kepuasan Kerja $(\mathrm{Y})$ & 0,791 & Valid/Rel. \\
\hline
\end{tabular}

Sumber: data diolah (2019)

Ni Luh Gede Putu Purnawati 
Jurnal Satyagraha

Vol.04, No.01, Pebruari 2021 - Agustus 2021

ISSN : 2620-6358

http://ejournal.universitasmahendradatta.ac.id/index.php/satyagraha

Hasil uji instrumen penelitian ialah uji validitas dan uji reliabilitas menunjukkan bahwa seluruh instrumen penelitian yang digunakan untuk mengukur variabel komunikasi, budaya organisasi, lingkungan kerja, dan kepuasan kerja ini memiliki suatu nilai koefisien korelasi dengan skor total seluruh item pernyataan lebih besar dari 0,30 dan memiliki koefisien Cronbach's Alpha lebih dari
0,60. Dengan demikian menunjukkan bahwa butir-butir pernyataan dalam instrumen penelitian tersebut valid dan reliabel, sehingga layak digunakan sebagai instrumen dalam penelitian.

Mengenai uji normalitas, uji multikolinearitas dan uji heteroskedastisitas yang telah dirangkum dalam Tabel 5 sebagai berikut:

Tabel 5. Uji Asumsi Klasik

\begin{tabular}{|c|c|c|c|c|c|}
\hline \multirow[b]{2}{*}{ Uji Normalitas } & & \multirow[b]{2}{*}{ Var. } & \multicolumn{2}{|c|}{ Uji Multikolinerairas } & \multirow{2}{*}{$\begin{array}{l}\text { Uji } \\
\text { Heteroskedastisi } \\
\text { tas }\end{array}$} \\
\hline & & & Tol. & VIF & \\
\hline $\mathrm{N}$ & 10 & $\mathrm{X} 1$ & 0,625 & 1,352 & 0,774 \\
\hline $\begin{array}{l}\text { Kolmogorov- } \\
\text { Smirnov Z }\end{array}$ & 0,914 & $\mathrm{X} 2$ & 0,613 & 1,528 & 0,748 \\
\hline $\begin{array}{l}\text { Asymp } \\
\text { tailed) }\end{array}$ Sig (2- & 0,324 & X3 & 0,735 & 1,475 & 0,437 \\
\hline
\end{tabular}

Sumber: data diolah (2019)

Seluruh uji asumsi klasik dalam Tabel 5 sudah terpenuhi, maka selanjutnya menjelaskan hasil analisis regresi linier berganda. Dengan perhitungan koefisien regresi linier berganda dilaksanakan dengan analisis regresi melalui software SPSS versi 18.0., maka diperoleh hasil yang ditunjukan pada Tabel 6 .

Tabel 6. Analisis Regresi

\begin{tabular}{|c|c|c|c|c|c|}
\hline \multirow{2}{*}{ Model } & \multirow{2}{*}{$\begin{array}{l}\text { Unstd. } \\
\text { Coef. } \\
\text { Beta }\end{array}$} & \multicolumn{2}{|l|}{ Std. Coef. } & \multirow[t]{2}{*}{$\mathrm{t}$} & \multirow[t]{2}{*}{ Sig } \\
\hline & & Std Error & Beta & & \\
\hline 1 (constant) & 2,142 & 1,624 & & 1,466 & 0,167 \\
\hline $\mathrm{X} 1$ & 0,246 & 0,134 & 0,245 & 2,845 & 1,101 \\
\hline $\mathrm{X} 2$ & 0,488 & 0,121 & 0,478 & 5,245 & 0,000 \\
\hline $\mathrm{X} 3$ & 0,370 & 0,134 & 0,259 & 3,163 & 0,002 \\
\hline R Square & & & & & 0,156 \\
\hline $\begin{array}{l}\text { Adjusted R } \\
\text { Square }\end{array}$ & & & & & 40,114 \\
\hline $\begin{array}{l}\text { Signifikansi } \\
\text { Uji F }\end{array}$ & & & & & 0,008 \\
\hline
\end{tabular}

Sumber: data diolah (2019)

Berdasarkan hasil dari kesimpulan analisis regresi linier berganda seperti yang disajikan pada Tabel 6, dapat dilihat besarnya pengaruh variabel bebas terhadap variabel terikat yang ditunjukkan oleh nilai determinasi total (Adjusted $\mathrm{R}$ Square) adalah sebesar 0,401 yang memiliki makna bahwa sebesar $40,1 \%$ variasi kepuasan 
Jurnal Satyagraha

Vol.04, No.01, Pebruari 2021 - Agustus 2021

ISSN : 2620-6358

http://ejournal.universitasmahendradatta.ac.id/index.php/satyagraha

kerja pegawai Mizu Villa dipengaruhi oleh variasi komunikasi, budaya organisasi, dan lingkungan kerja, sedangkan sisanya sebesar 59,9\% djelaskan oleh faktor lain yang tidak dimasukkan ke dalam model.

Hasil uji $\quad F \quad$ (F-test) pada Tabel 7 mencerminkan bahwa nilai signifikansi $\mathrm{P}$ value 0,000 yang lebih kecil dari $\alpha=0,05$, ini artinya model yang terapkan pada penelitian ini adalah layak. Hasil tersebut memberikan arti bahwa seluruh variabel independen bisa memprediksi atau memberikan suatu gambaran fenomena kepuasan kerja Mizu Villa. Hal ini berarti model tersebut dapat digunakan sebagai analisis selanjutnya atau dengan maksud lain model ini yaitu mampu digunakan sebagai proyeksi karena hasil goodness of fitnya baik dengan nilai signifikansi $\mathrm{P}$ value 0,000 . Hal tersebut mecerminkan bahwa informasi memberikan pengaruh secara simultan dari variabel komunikasi, budaya organisasi, dan lingkungan kerja terhadap kepuasan kerja karyawan.

Hasil dari analisis diperoleh pengaruh komunikasi terhadap kepuasan kerja terlihat pada Tabel 7 dengan nilai signifikansi sebesar 0,008 dan koefisien beta sebesar 0,246 yang artinya komunikasi berpengaruh secara positif dan signifikan terhadap kepuasan kerja pegawai Mizu Villa. Semakin baik komunikasi yang dilakukan di Mizu Villa maka akan semakin tinggi kepuasan kerja yang dirasakan oleh pegawai. Demikian juga semakin tidak bagus komunikasi yang dilakukan pada Mizu Villa, maka kepuasan kerja karyawan semakin berkurang.

Bagian yang paling penting dalam kehidupan kerja untuk mendapatkan kepuasan adalah menjalin komunikasi yang baik, artinya komunikasi yang tidak baik bisa memberikan dampak yang luas terhadap kehidupan organisasi, seperti terjadinya konflik antar pegawai, dan sebaliknya komunikasi yang baik dapat meningkatkan saling pengertian, kerja sama dan peningkatan kepuasan kerja. Mengingat dengan adanya sumber daya manusia yang banyak dan memiliki karakteristik yang berbeda maka diperlukan suatu keterbukaan dalam organisasi sehingga mampu mencapai tujuan. Komunikasi memiliki hubungan yang positif terhadap kepuasan kerja karyawan, artinya semakin baik komunikasi yang dilakukan maka semakin meningkatlah kepuasan yang dirasakan oleh seseorang (Mustika, 2013).

Penelitian ini mendukung hasil temuan penelitian sebelumnya yang dilakukan oleh Shakil (2012), Epure et al. (2013), Diatmika (2013), Siregar (2014), Riadi (2015), Wirawan dan Sudharma (2015), Supriambodo (2016), Riyadi dkk. (2017), serta Harahap dan Mahadewi (2017) yang menunjukkan bahwa komunikasi berpengaruh positif dan signifikan terhadap kepuasan kerja pegawai artinya semakin baik komunikasi yang dilakukan maka kepuasan kerja pegawai semakin meningkat.

Hasil dari analisis pengaruh budaya organisasi terhadap kepuasan kerja pada Tabel 7 diperoleh nilai signifikansi sebesar 0,000 dengan nilai koefisien beta 0,488 , artinya bahwa budaya organisasi berpengaruh positif dan signifikan terhadap kepuasan kerja pegawai Mizu Villa. Semakin kuat budaya organisasi pada Mizu Villa maka kepuasan kerja karyawan akan semakin meningkat. Begitu pula sebaliknya, semakin lemahnya budaya organisasi yang ada di Mizu Villa maka semakin rendah kepuasan kerja karyawan pada Mizu Villa. 
Jurnal Satyagraha

Vol.04, No.01, Pebruari 2021 - Agustus 2021

ISSN : 2620-6358

http://ejournal.universitasmahendradatta.ac.id/index.php/satyagraha

Pada Budaya organisasi terkandung nilai, sikap, keyakinan, dan norma-norma organisasi yang berpengaruh terhadap efektivitas organisasi dan kepuasan kerja anggota. Dengan demikian nilai-nilai dan norma-norma yang terkandung dalam organisasi akan berpengaruh pada kepuasan kerjanya (Refi, 2015).

Penelitian ini sesuai dengan hasil temuan penelitian Abadiyah dan Purwanto (2016) yang menunjukkan budaya organisasi berpengaruh terhadap kepuasan kerja. Apabila perusahaan memiliki budaya organisasi yang baik, maka pegawai akan lebih disiplin dan mampu menyelesaikan tugas secara efektif dan efesien yang akan menimbulkan kepuasan kerja. Penelitian ini juga didukung oleh hasil temuan penelitian Lestari dan Hutami (2014), Susetyo dkk. (2014), Herawan dkk. (2015), Yusuf (2016), Lagonah dkk. (2016), serta Wibowo dan Putra (2016) yang menyatakan bahwa budaya oganisasi berpengaruh positif dan signifikan terhadap kepuasan kerja. Semakin baik penerapan budaya organisasi maka kepuasan kerja karyawan semakin meningkat.

Hasil analisis dari pengaruh lingkungan kerja terhadap kepuasan kerja pada Tabel 7 diperoleh nilai signifikansi sebesar 0,002 dengan nilai koefisien beta 0,370 . Nilai signifikansi $0,002<0,05$ mengindikasikan bahwa $\mathrm{H} 0$ ditolak dan $\mathrm{H} 3$ diterima. Hasil temuan penelitian ini mempunyai arti bahwa lingkungan kerja berpengaruh positif dan signifikan terhadap kepuasan kerja pegawai Mizu Villa.

Semakin nyaman lingkungan kerja dalam organisasi maka semakin meningkat kepuasan kerja pegawai Mizu Villa. Begitu pula sebaliknya, semakin buruk kondisi lingkungan kerja pada Mizu Villa maka semakin berkurangnya kepuasan kerja pegawai. Lingkungan kerja yang baik akan mendukung kondisi kerja karyawan. Karyawan membutuhkan lingkungan kerja yang baik, selain untuk kenyamanan juga sebagai faktor pendukung dalam melaksanakan pekerjaannya. Dengan rasa puas pada diri karyawan akan mampu meningkatkan kerja karyawan (Pangestu dkk., 2017). Penelitian ini mendukung beberapa hasil temuan penelitian (Wibowo et al,. 2014) yang menunjukkan bahwa lingkungan kerja fisik mempunyai pengaruh signifikan terhadap kepuasan kerja. Tingkat signifikansi memiliki makna bahwa lingkungan kerja fisik memiliki peranan yang penting untuk meningkatkan kepuasan kerja. Hasil temuan penelitian ini juga didukung oleh Rumada dan Utama (2013), Riadi (2015), Wirawan dan Sudharma (2015), Aruan dan Fakhri (2015), Haedar dkk. (2015), Putri dkk. (2016), Yusuf (2016), Husni dkk. (2018), dan Sari (2018) yang menunjukkan bahwa lingkungan kerja berpengaruh positif dan signifikan pada kepuasan kerja karyawan yang berarti semakin baik lingkungan kerja fisik, maka kepuasan kerja akan semakin meningkat. Lingkungan kerja yang baik dan terjaga akan membuat karyawan merasa tenang dan nyaman sehingga kepuasan kerja akan meningkat. 
Jurnal Satyagraha

Vol.04, No.01, Pebruari 2021 - Agustus 2021

ISSN : 2620-6358

http://ejournal.universitasmahendradatta.ac.id/index.php/satyagraha

\section{SIMPULAN DAN SARAN}

Simpulan

Berdasarkan hasil temuan penelitian maka dapat disimpulkan, yaitu: 1) komunikasi berpengaruh positif dan signifikan terhadap kepuasan kerja, yang artinya semakin baik komunikasi yang terjadi di Mizu Villa maka semakin tinggi kepuasan kerja yang dirasakan pegawai; 2) budaya organisasi berpengaruh positif dan signifikan terhadap kepuasan kerja, artinya bahwa semakin kuat budaya organisasi yang terbentuk di Mizu Villa maka kepuasan kerja karyawan akan semakin meningkat; 3) lingkungan kerja berpengaruh positif dan signifikan terhadap kepuasan kerja, artinya semakin baik kondisi lingkungan kerja maka akan berpengaruh pada semakin meningkatnya kepuasan kerja pegawai Mizu Villa.

\section{Saran}

Saran yang dapat diberikan berdasarkan hasil penelitian adalah 1) dalam upaya meningkatkan komunikasi menjadi lebih baik, maka Mizu Villa diharapkan memberikan pelatihan dan pendidikan bagi karyawannya mengenai cara berdiskusi yang tepat dalam menemukan solusi pada permasalahan kerja yang dihadapi. Apabila karyawan mampu berdiskusi dengan efektif dalam menemukan solusi permasalahan pekerjaan, maka komunikasi akan semakin baik; 2) dalam upaya meningkatkan budaya organisasi pegawai, maka Mizu Villa diharapkan membuat sanksi yang lebih tegas; 3) dalam upaya meningkatkan lingkungan kerja menjadi lebih baik, maka pihak manajemen Mizu Villa diharapkan rutin melakukan evaluasi terhadap fasilitas yang disediakan Villa dalam menunjang pekerjaan karyawannya; 4) dalam upaya meningkatkan kepuasan kerja pegawai menjadi lebih baik, maka pihak manajemen Mizu Villa diharapkan melakukan evaluasi pada gaji atau upah yang sudah diberikan pada karyawannya apakah sudah sesuai dengan beban kerja yang diterima. Apabila karyawan merasa puas dengan bayaran yang diberikan oleh perusahan karena sudah adil dan sudah sesuai sama beban kerja yang diterima, maka hal tersebut dapat meningkatkan kepuasan kerja karyawan.

\section{DAFTAR PUSTAKA}

Aruan,Quinerita Stevani dan Mahendra Fakhri (2015). Pengaruh Lingkungan Kerja Terhadap Kepuasan Kerja Karyawan Lapangan Departemen Grasberg Power Distribution PT. Freeport Indonesia. Jurnal MODUS 27(2): 141-162

Cekmecelioglu, Hulya Gunduz., Ayse Gunseland Tugce Ulutas. (2012). Effects Of Emotional Intelligence On Job Satisfaction: An Empirical Study On Call Center Employees. Procedia-Social and Behavioral Sciences, 58,pp: 363-369.

Diatmika, Paripurna. (2013). Pengaruh Lingkungan Kerja, Komunikasi Terhadap Kepuasan Kerja Karyawan. E-journal Manajemen Unud, 2 (5): 581-593.

Epure, Danut Tiberius., Alexandra Ionescu, and Dorinela Nancu. (2013). The Impact of Communication in Job Satisfaction: an Empirical Investigation within Romanian Companies. Journal Economics and Applied Informatics. 19(2): 71-74 
Jurnal Satyagraha

Vol.04, No.01, Pebruari 2021 - Agustus 2021

ISSN : 2620-6358

http://eiournal.universitasmahendradatta.ac.id/index.php/satyagraha

Haedar., Sharuddin, dan Herlangga. (2015). Pengaruh Lingkungan Kerja Dan Masa Kerja Terhadap Kepuasan Karyawan Pada PT. Hadji Kalla Palopo. Jurnal Manajemen. 2(1): 10-22.

Harahap, Zulkifli., dan Ni Made Eka Mahadewi. (2017). Pengaruh Komunikasi Terhadap Kepuasan Kerja Karyawan Hotel (Studi Kasus Hotel Bintang 4 dan 5 di Destinasi Wisata Jawa Barat). Jurnal Kepariwisataan.16(1): 3546

Herawan, Koko., M. Djudi Mukzam, dan Gunawan Eko Nurtjahjono. (2015). Pengaruh Budaya Organisasi Terhadap Kepuasan Kerja Karyawan Studi Pada PT. Bank Rakyat Indonesia (Persero) Kantor Cabang Kota Malang Kawi. Jurnal Administrasi Bisnis. 18(1): 1-6

Husni., Said Musnadi, Faisal. (2018). Pengaruh Lingkungan Kerja, Kompensasi Dan Motivasi Terhadap Kepuasan Kerja Serta Dampaknya Terhadap Loyalitas Kerja Pegawai Rutan di Provinsi Aceh (Studi Kasus Pada Rutan Klas Iib Banda Aceh Dan Rutan Klas Ii B Jantho. Jurnal Magister Manajemen. 2(1):88-98

Julianto, Romi Haryo dan Susi Hendriani. (2014). Pengaruh Budaya Organisasi dan Motivasi Kerja Terhadap Kepuasan Kerja dan Kinerja Pegawai Pada Kantor Wilayah Direktorat Jenderal Bea dan Cukai (DJBC) Riau dan Sumatera Barat. Jurnal Ekonomi. Vol. 22, No. 2, Hal: 13-26

Lagonah, Srijanti., Rianoe Pio, dan Markus Kaunang. (2016). Pengaruh Iklim
Organisasi Dan Budaya Organisasi Terhadap Kepuasan Kerja Pegawai Kantor Pertanahan Kota Manado. Jurnal Ilmiah Society. 1(24): 1-19

Lestari, Anjani Puji., dan Rr. Rieka Febriyanti Hutami. (2014). Pengaruh Budaya Organisasi Terhadap Kepuasan Kerja Karyawan Telkom Foundation (TF). Jurnal Manajemen Bisnis Telekomunikasi dan Informatika. Pp: 1-8

Mariani, Luh Mang Indah., dan Ni Ketut Sariyathi. (2017). Pengaruh Motivasi, Komunikasi Dan Disiplin Kerja Terhadap Kinerja Karyawan Warung Mina Peguyangan Di Denpasar. E-Jurnal Manajemen Unud. 6(7): 35403569

Mustika. (2013). Analisis Pengaruh Komunikasi Organisasi dan Komitmen Keorganisasian Terhadap Kepuasan Kerja Karyawan PT. BTPN Tbk KCP Pasar Baru Merangin. Jurnal Dinamika Manajemen. 1(3): 215-224.

Pangestu, Zulfahmi Septian., Mochammad Djudi Mukzam dan Ika Ruhana. (2017). Pengaruh Lingkungan Kerja Terhadap Kepuasan Kerja (Studi pada Karyawan Perum Perhutani Ngawi). Jurnal Administrasi Bisnis (JAB). 43(1):157-162

Putri, Sari Dewi. (2016). Pengaruh Lingkungan Kerja Terhadap Kepuasan Kerja Karyawan Hotel Grand Rocky Bukittinggi. E-Journal Home Economic and Tourism. 13(3): 1-17 
Jurnal Satyagraha

Vol.04, No.01, Pebruari 2021 - Agustus 2021

ISSN : 2620-6358

http://ejournal.universitasmahendradatta.ac.id/index.php/satyagraha

Refi, Teuku Muana. (2015).Pengaruh Budaya Organisasi Terhadap Kepuasan Kerja Karyawan Bank Syariah Mandiri Cabang Banda Aceh. Jurnal Ekonomi Manajemen Dan Bisnis. 3(1):475-486

Riduwan dan Sunarto, (2007), Pengantar Statiska Untuk Penelitian Pendidikan, Sosial, Ekonomi, dan Bisnis, Penerbit alfabeta, Bandung.

Riyadi, Heru., Bambang Sapto Utomo, dan Anwari Masatip. (2017). Pengaruh Komunikasi, Motivasi Kerja dan Kompetensi Terhadap Kepuasan Kerja Serta Implikasinya Pada Kinerja Dosen Pada Perguruan Tinggi Pariwisata Swasta Di Jawa Barat. Tourism and Hospitality Essentials (THE) Journal. 7(2): 7390

Rumada, Gede dan Utama, Mudiartha, (2013). Pengaruh Kompensasi, Lingkungan Kerja Fisik Terhadap Kepuasan Kerja Karyawan Hotel Taman Harum Ubud Gianyar.EJurnal Manajemen Universitas Udayana, 2(1): 106-120

Santoso, Agus. (2018). Pengaruh Efikasi Diri, Motivasi Kerja, Dan Lingkungan Kerja Terhadap Kepuasan Kerja Pegawai PT. Sukanda Djaya Cabang Denpasar. EJurnal Manajemen Universitas Udayana, 7(10): 1617-1643

Sari, Dewi Puranama. (2018). Pengaruh Lingkungan Kerja Dan Disiplin Kerja Terhadap Kepuasan Kerja Guru Sekolah Menengah Kejuruan (SMK) Swasta Sekecamatan Pondok
Aren. Jurnal Saintika Unpam. 1(1):108-132

Shakil, M. Ahmad. (2012). ImpactOf Organizational Culture On Performance Management Practices in Pakistan. Bussines Intelligence Journal. 5(1) : p: 50-55

Siregar, Siti Zubaidah. (2014). Pengaruh Budaya Organisasi dan Komunikasi Terhadap Kepuasan Kerja Serta Dampaknya Pada Kinerja Guru Sekolah Dasar Negeri di Kota Sibolga. Tesis. Universitas Terbuka.

Sugiyono. (2016). Metode Penelitian Kuantitatif Kualitataif dan Kombinasi (Mixed Methods). Bandung: Alfabeta.

Supriambodo, Agung. (2016). Pengaruh Komunikasi Terhadap Kepuasan Kerja Karyawan (Studi Pada CV Solaris Service Sentosa Kota Sidoarjo). Jurnal Ilmu Sosial dan Ilmu Politik Universitas Muhammadiyah, hal:1-28

Susetyo, Widyanto Eko., Amiartuti Kusmaningtyas, dan Hendro Tjahjono. (2014). Pengaruh Budaya Organisasi Dan Lingkungan Kerja Terhadap Kepuasan Kerja Dan Kinerja Karyawan Pada PT. Bank Muamalat Indonesia Divisi Konsumer Area Cabang Surabaya. Jurnal Ilmu Ekonomi \& Manajemen. $1(1), 83-93$

Suryaningsih, Eka Putri, (2012). Pengaruh Budaya Organisasi, Komunikasi dan Lingkungan Fisik Terhadap Kepuasan Kerja Karyawan Pada 
Jurnal Satyagraha

Vol.04, No.01, Pebruari 2021 - Agustus 2021

ISSN : 2620-6358

http://eiournal.universitasmahendradatta.ac.id/index.php/satyagraha

Mizu Villa di Kuta Kabupaten Badung. Jurnal Manajemen. Fakultas Ekonomi Universitas Mahasaraswati. Hal:1-6

Wibowo, Mukti., Mochammad Al Musadieq dan Gunawan Eko Nurtjahjono. (2014). Pengaruh Lingkungan Kerja Terhadap Kepuasan Kerja Karyawan (Studi pada Karyawan PT. Telekomunikasi Indonesia Tbk. Kandatel Malang). Jurnal Administrasi Bisnis (JAB). 16(1): 19

Wibowo, Mada Adi., dan Yanuar Surya Putra. (2016). Pengaruh Motivasi Dan Budaya Organisasi Terhadap Kepuasan Kerja Serta Implikasinya Terhadap Kinerja Karyawan Pada Rumah Sakit Umum (RSU) Salatiga. Jurnal Ilmiah Among Makarti. 9(17): $1-20$
Wernerfelt (1984). Teori RBV ini memandang bahwa sumber daya dan kemampuan perusahaan penting bagi perusahaan, karena merupakan pokok atau dasar dari kemampuan daya saing serta kinerja perusahaan.

Wirawan, I Dewa Gede Kresna., dan I Nyoman Sudharma. (2015). Pengaruh Komunikasi, Motivasi dan Lingkungan, Kerja Fisik Terhadap Kepuasan Kerja Pegawai Sekretariat Daerah Kota Denpasar. E-Jurnal Manajemen Unud. 4(10): 3037-3062.

Yusuf, Muhammad. (2016). Pengaruh Gaya Kepemimpinan Dan Budaya Organisasi Terhadap Kepuasan Kerja Dan Kinerja Guru Militer Resimen Induk Komando Daerah Militer Vii/Wirabuana Di Sulawesi. Jurnal Bisnis dan Kewirausahaan. 5(2): 219-236 